\title{
Age and gender related differences in aortic blood flow
}

Traberg, Marie Sand; Pedersen, Mads Møller; Hemmsen, Martin Christian; Lönn, Lars; Henneberg, KajÅge; Jensen, Jørgen Arendt

\section{Published in:}

Proceedings of SPIE

Link to article, DOI:

$10.1117 / 12.910859$

Publication date:

2012

Document Version

Early version, also known as pre-print

Link back to DTU Orbit

Citation (APA):

Traberg, M. S., Pedersen, M. M., Hemmsen, M. C., Lönn, L., Henneberg, K-Å., \& Jensen, J. A. (2012). Age and gender related differences in aortic blood flow. In J. G. Bosch, \& M. M. Doyley (Eds.), Proceedings of SPIE (Vol. 8320). [83200J] SPIE - International Society for Optical Engineering. https://doi.org/10.1117/12.910859

\section{General rights}

Copyright and moral rights for the publications made accessible in the public portal are retained by the authors and/or other copyright owners and it is a condition of accessing publications that users recognise and abide by the legal requirements associated with these rights.

- Users may download and print one copy of any publication from the public portal for the purpose of private study or research.

- You may not further distribute the material or use it for any profit-making activity or commercial gain

- You may freely distribute the URL identifying the publication in the public portal 


\title{
Age and gender related differences in aortic blood flow
}

\author{
Marie S. Enevoldsen ${ }^{1}$, Mads M. Pedersen², Martin C. Hemmsen ${ }^{1,3}$, Lars Lönn², Kaj-Åge \\ Henneberg ${ }^{1}$ and Jørgen A. Jensen ${ }^{1}$ \\ ${ }^{1}$ Department of Electrical Engineering, Technical University of Denmark, 2800 Lyngby, \\ Denmark; \\ 2Department of Radiology, Copenhagen University Hospitalet, 2100 Copenhagen, Denmark; \\ ${ }^{3}$ B-K Medical, 2730 Herlev, Denmark
}

\begin{abstract}
The abdominal aorta (AA) is predisposed to development of abdominal aneurysms (AAA), a focal dilatation of the artery with fatal consequences if left untreated. The blood flow patterns in the AA is thought to play an important role in the development of AAA. The purpose of this work is to investigate the blood flow patterns within a group of healthy volunteers ( 4 females, 7 males) aged 23 to 76 years to identify changes and differences related to age and gender. The healthy volunteers were categorized by gender (male/female) and age (below/above 35 years). Subject-specific flow and geometry data were acquired using the research interface on a medical ultrasound scanner and segmentation of 3D magnetic resonance angiography respectively. The largest average diameter was among the elderly males $(19.7( \pm 1.33) \mathrm{mm})$ and smallest among the young females $(12.4$ $( \pm 0.605) \mathrm{mm})$. The highest peak systolic velocity was in the young female group $(1.02( \pm 0.336) \mathrm{m} / \mathrm{s})$ and lowest in the elderly male group $(0.836( \pm 0.127) \mathrm{m} / \mathrm{s})$. A geometrical change with age was observed as the AA becomes more bended with age. This also affects the blood flow velocity patterns, which are markedly different from young to elderly. Thus, changes in blood flow patterns in the AA related to age and gender is observed. Further investigations are needed to determine the relation between changes in blood flow patterns and AAA development.
\end{abstract}

Keywords: Blood flow estimation, abdominal aorta, aneurysms, spectral measurements, magnetic resonance angiography

\section{DESCRIPTION OF PURPOSE}

Cardiovascular disease is a leading cause of death and accounted for $30 \%$ of all deaths in 2005 according to WHO. ${ }^{1}$ Here focus is on the abdominal aorta (AA), which is prone to development of abdominal aortic aneurysms (AAA). AAA is a focal pathological dilatation of the AA which may rupture if left untreated, and the blood flow patterns of the AA is thought to play an important role. ${ }^{2}$ The purpose of this work is to investigate blood flow patterns in the AA to identify changes and differences related to age and gender, as it is expected that these changes can increase the knowledge of the role of blood flow patterns in AAA development. The study is performed using subject-specific flow and geometry data from a group of healthy volunteers aged 23 to 76 years.

\section{METHODS}

\subsection{Data acquisition}

Subject-specific blood flow velocity profiles are now easily obtained with the implementation of research interfaces on commercial ultrasound scanners ${ }^{3,4}$ enabling extraction of raw spectral data from the flowing blood suitable for reconstruction of the spatial-temporal velocity profile. Here, a UA2227 research interface implemented on a 2202 ProFocus scanner (B-K Medical, Herlev Denmark) ${ }^{5}$ was used to acquire subject-specific spectral data from the AA. The range gate was set to cover the entire AA diameter. 4 females (28-57 years old) and 7 males (23-76 years old) were scanned using a convex array transducer (BK8803, B-K Medical, Herlev, Denmark) and several data sequences of five seconds each were acquired for each volunteer. The lumen geometry of each AA was obtained by segmentation of 3D magnetic resonance angiography (Magnetom Trio, Siemens Healthcare, Erlangen, Germany).

Send correspondence to Marie S. Enevoldsen, E-mail: mse@elektro.dtu.dk 


\subsection{Data processing - spectral measurements}

The mean spatial velocity $\bar{v}$ in the AA was estimated using the power spectrum of the recorded spectral data. The data was acquired real-time and processed off line using Matlab R2010a (Mathworks Inc., Natick, MA, United States). From Fourier decomposition of $\bar{v}$ the temporal and spatial evolution can be calculated using the Womersley-Evans method. ${ }^{6}$ Neglecting entrance effects the spatial-temporal velocity profile for each subject was calculated as:

$$
v\left(t, \frac{r}{R}\right)=2 v_{0}\left(1-\left(\frac{r}{R}\right)^{2}\right)+\sum_{m=1}^{\infty}\left|V_{m}\right|\left|\psi_{m}\right| \cos \left(m \omega t-\phi_{m}+\chi_{m}\right),
$$

where $v_{0}$ is the average velocity, $V_{m}$ is the amplitude of the Fourier decomposistion, $\psi_{m}$ is a function describing the velocity changes with time and position during one cardiac cycle, $\omega$ is the mean frequency, $\phi_{m}$ is the phase of the Fourier decomposition, and $\chi_{m}$ is the angle of $\psi_{m} \cdot{ }^{7}$

\subsection{Data processing - computational fluid dynamics}

The AA lumen for each volunteer was obtained by segmentation of 3D magnetic resonance angiography using ScanIP (Simpleware ldt., Exeter, United Kingdom). The geometry included the iliac bifurcation, and was cut just below the branching of the renal arteries. The lumen geometry was loaded into COMSOL Multiphysics v4.2 (COMSOL AB, Stockholm, Sweden) and meshed using a user-defined mesh algorithm. The subject-specific velocity was applied as inlet boundary condition with a corresponding physiological outlet pressure of $120 \mathrm{mmHg}$. No-slip condition was applied to the wall. The blood was assumed to be a Newtonian fluid with $\rho=1,060 \mathrm{~kg} / \mathrm{m}^{3}$ and $\mu=3.5 \cdot 10^{-3} \mathrm{~Pa} \cdot \mathrm{s}$. The velocity field was calculated using the time-dependent Navier-Stokes equation.

\section{RESULTS}

Four clinical parameters were chosen for comparison regarding the blood flow velocity estimations; age, aortic diameter, velocity in the peak systole (PS), and velocity at the end diastole (ED). The results are summarized in Table 1.

Table 1. Blood flow velocity parameters for the 11 volunteers.

\begin{tabular}{|l|c|c|c|c|}
\hline Parameter & \multicolumn{2}{|c|}{ Males } & \multicolumn{2}{c|}{ Females } \\
\hline Age & $<35$ years & $\geq 35$ years & $<35$ years & $\geq 35$ years \\
\hline Aortic diameter $(\mathrm{mm})$ & $17.5( \pm 1.60)$ & $19.7( \pm 1.33)$ & $12.4( \pm 0.605)$ & $17.0( \pm 0.113)$ \\
\hline PS velocity $(\mathrm{m} / \mathrm{s})$ & $0.978( \pm 0.145)$ & $0.836( \pm 0.127)$ & $1.02( \pm 0.336)$ & $0.891( \pm 0.027)$ \\
\hline ED velocity $(\mathrm{m} / \mathrm{s})$ & $-0.075( \pm 0.016)$ & $-0.059( \pm 0.018)$ & $-0.069( \pm 0.004)$ & $-0.072( \pm 0.009)$ \\
\hline
\end{tabular}

The AA diameter increases with age for both genders. The average diameter among males is larger compared to the female group. Comparing the velocity at PS and ED the highest positive velocity (forward flow towards the iliac bifurcation) is in the young group of both genders. The velocity at ED is more even in magnitude among the volunteers, except in the group of elderly males where the velocity is lower. As an example of the velocity profile reconstruction, the case of a 51 years old (y.o.) male is illustrated in Figure 1 and 2. Figure 1 shows the spectrogram of one data sequence. Figure 2 shows the reconstructed subject-specific velocity profile at 6 points during the cardiac cycle. In Figure 3 the geometrical divergence is illustrated. The marked influence of the geometry on the velocity field is seen in Figure 4 where a young female and an elderly male are compared. 


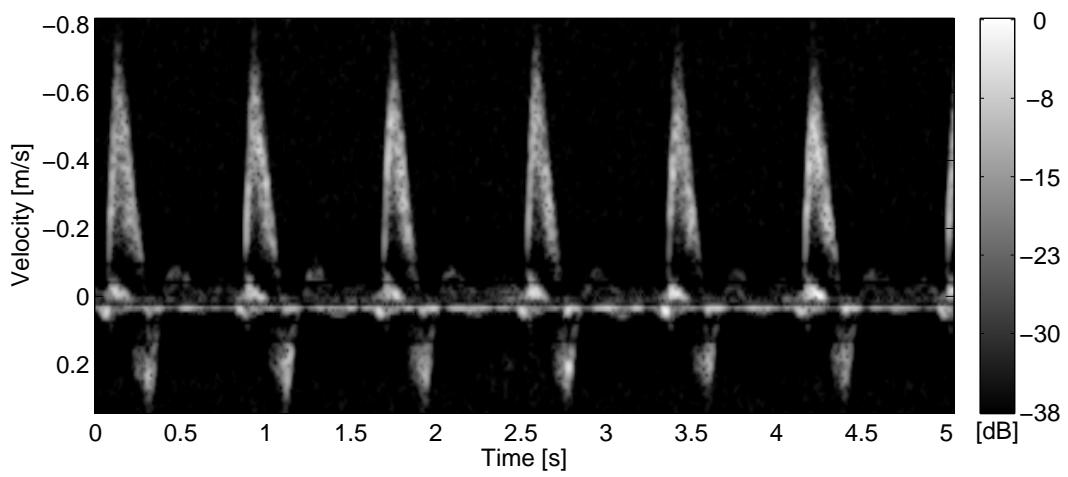

Figure 1. Example of calculated spectrogram for a 51 y.o. male.

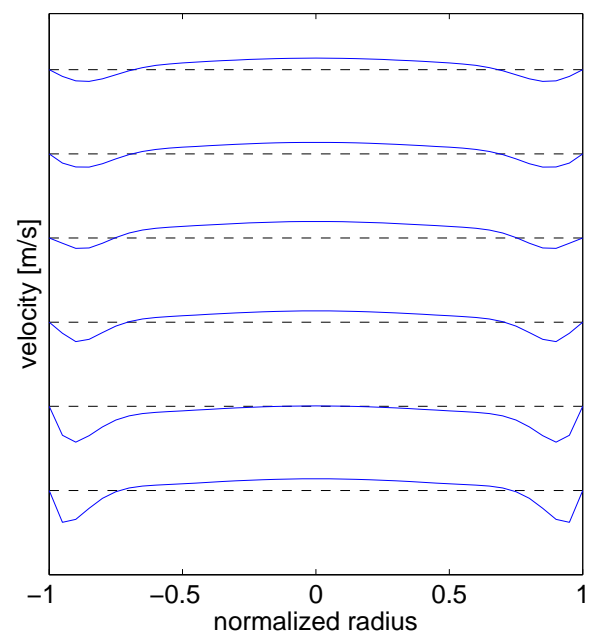

Figure 2. The velocity profile in the AA at 6 random times during a single cardiac cycle for a 51 y.o. male. The dashed line corresponds to baseline.

\section{NEW WORK TO BE PRESENTED}

A study on the differences in blood flow patterns and geometric configuration in a group of healthy volunteers aged 23 to 76 years is presented. The results indicate that there is a significant difference in flow and geometry related to age and gender. This motivates for further research on how differences in the blood flow patterns can be related to AAA development.

\section{CONCLUSIONS}

Demographic differences in blood flow patterns and AA geometry within a population of healthy volunteers are shown. The AA changes in geometrical configuration with age, which also affect the blood flow patterns (see Figure 3 and 4 ). The easy access to both blood flow velocity data and geometrical information presented here provides a powerful tool for further research in the role of blood flow patterns in development of AAA. 


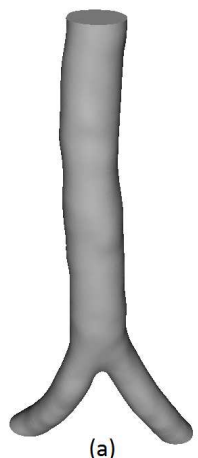

(a)

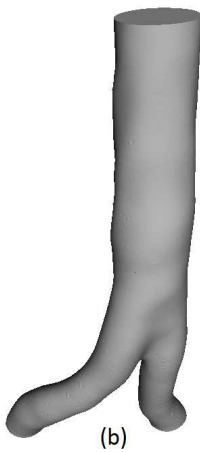

(b)

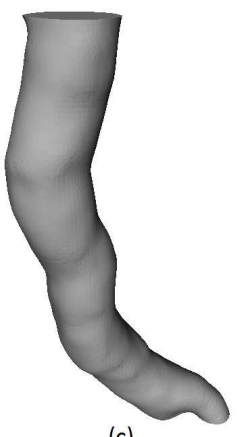

(c)

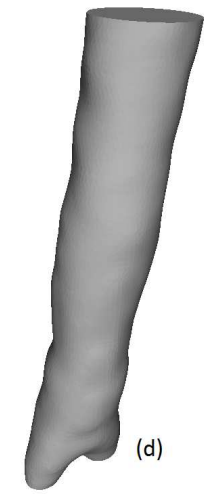

Figure 3. Example of the geometric diversity among the volunteers. (a) 28 y.o. female, (b) 51 y.o. female, (c) 76 y.o. male, and (d) 51 y.o. male.
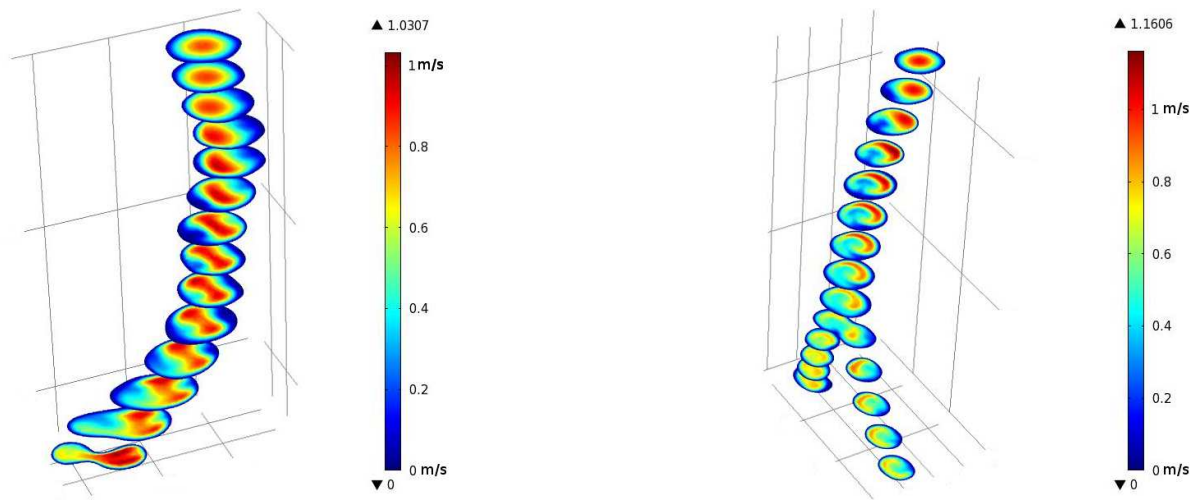

Figure 4. Example of the blood flow velocity pattern at PS in the AA. The distribution of velocity in the AA of a 76 y.o. male is shown to the left. To the right the velocity distribution in the AA of a 28 y.o. female is shown. Geometries are not to scale.

\section{CONFLICTS OF INTEREST}

There is no conflict of interest. This work has not been submitted for publication or presentation elsewhere.

\section{REFERENCES}

[1] WHO, "Cardiovascular Diseases (CVDs)." http://www.who.int/mediacentre/factsheets/fs317/en/ index.html, 2005. [Online; accessed 7-July-2011].

[2] J. D. Humphrey and C. A. Taylor, "Intracranial and abdominal aortic aneurysms: similarities, differences, and need for a new class of computational models," Annual review of biomedical engineering 10, p. 221, 2008.

[3] S. Brunke, M. Insana, J. Dahl, C. Hansen, M. Ashfaq, and H. Ermert, "Errata - an ultrasound research interface for a clinical system," Ultrasonics, Ferroelectrics and Frequency Control, IEEE Transactions on 54, pp. 198-210, January 2007.

[4] V. Shamdasani, U. Bae, S. Sikdar, Y. M. Yoo, K. Karadayi, R. Managuli, and Y. Kim, "Research interface on a programmable ultrasound scanner," Ultrasonics 48(3), pp. 159-168, 2008.

[5] M. Hemmsen, M. Pedersen, S. Nikolov, M. Nielsen, and J. Jensen, "Ultrasound image quality assessment: A framework for evaluation of clinical image quality," in SPIE, 2010.

[6] D. H. Evans, "Some aspects of the relationship between instantaneous volumetric blood flow and continuous wave Doppler ultrasound recordings III," 8, pp. 617-623, 1982b.

[7] J. A. Jensen, Estimation of Blood Velocities Using Ultrasound: A Signal Processing Approach, Cambridge University Press, New York, 1996. 